Metastable Ferrous Austenlte $=$ Consequences on Fracture and Trí

I. Schmidt, Zahnradfabrik Friedrichshafen AG, Friedrichshafen, FRG

\title{
Introduction
}

It is well known that a certain number of austenltic or partlally austenitic alloys exhibit drastical changes of properties when these materials can undergo a martensitic transformation induced by deformation. These changes can refer to e.g. density, shape. hardness, strength, ductility, fatigue crack growth, fracture toughness, wear resistance, corrosion resistance, permeability.

It is the aim of the present paper to explain the principle mechanism and to demonstrate the necessary prerequisites which must be fulfilled if metastable ferrous austenites should be turned to a good account in mechanical englneering. Aspects on Eracture and wear resistance are placed into the foreground.

\section{General Aspects}

Since the work of Scheil (1) in 1932 concerning the effects of stress on the formation of martensite many investigations have been made in this fleld. Among the phenomena that have been oboerved are the change in the martensite start temperature $M_{s}$ with the application of stres8, the stimulation of martensite formation by plastic deformation, mechanical stabilization effects. The main aspects have been summarized and discussed in general (review) articles on the martensitic transformation $(2$ - 7). A systematic analysis of the effect of all variables on the martensitic transformation teinperatures is given by Hornbogen (8). The following concentrates on essentials.

Stable austenites never transform to martensite. They are found in tough structural alloy steel. high alloy stainless steel or casting. wear resistant steel. The latter is known as hadfield steel (Fe-l2Mn-1.2C). Its high work-hardening rate is explained by the large composition of substitutional atoms (Mn) which considerably lowers the stacking fault energy and by dynamic strain aging brought about by the reorlentation of carbon atoms or carbon -manganese couples in the cores of dislocations (9).

In metastable austenites an additional contribution to rapid workhardening is due to the deformation-induced generation of martensite. The martensitic transformation starts spontaneously on cooling at $M_{s}=T_{0}-\Delta T$. Above $M_{s}$ it can be induced by external stresses. This stress-induced phase transformation occurs when a shear stress $\tau_{a m}$ acts in the direction of the martensitic shear which would have occured below $M_{s}$ without the application of external forces. $\tau_{a n}$ is zero at the martensite start temperature $M_{s}$, and increases with decreasing undercooling $\Delta T<T_{0}-M_{s}$, $i . e$. with decreasing chemical driving force for the martensitic transformation (Fig. $(10,7)$. It has been observed (11) that at tem- 


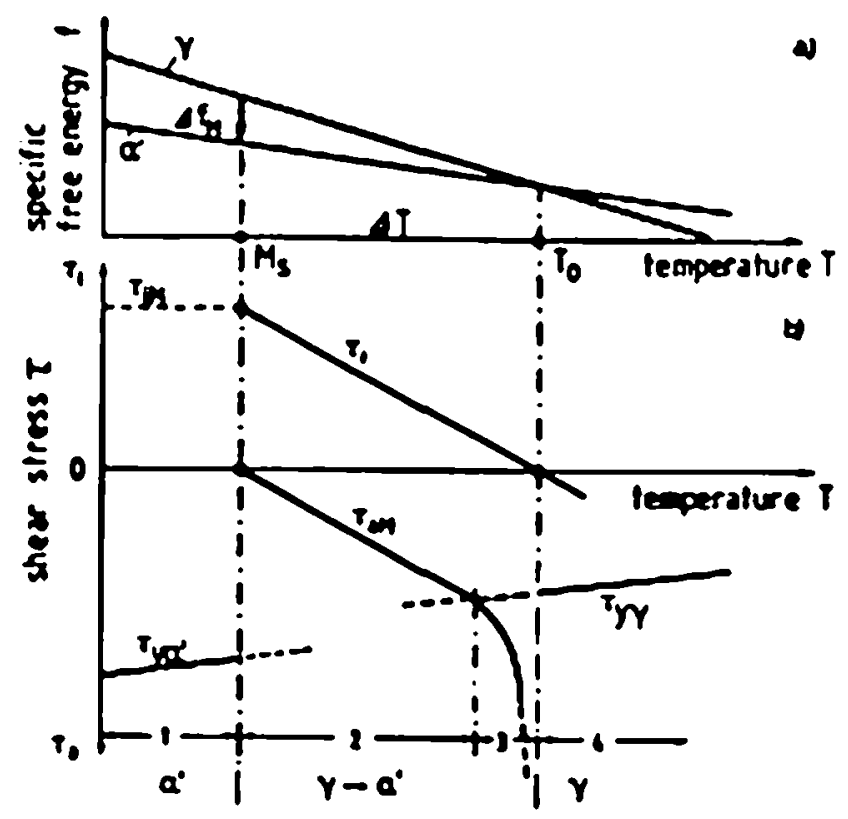

Fig. 1: Schematic representation of thermo-dynamical and mechanical propertles of an undorcooled high temperature phase $y$ $(10)$. a) Terporature dependence of specific free energy $f$ of the phases $\gamma$ and $\alpha^{\prime}$ b) At $T<T_{0}$ the Internal shear stress increases which induces spontaneous transformation at $\tau_{l}=\tau_{i n}$. According to the undercooling $A T$ the extornal shear stress tan necessary to cause transformation is reduced due to an increasing internal shear stress $\tau_{i}$. Tom becomes zero at $T$. Ms.

Range $1, f / \alpha^{\prime}$-transformation occurs by cooling.

External shear etress is not necossary.

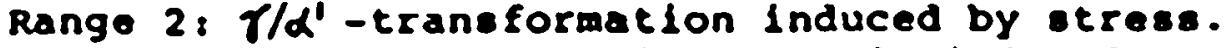

Range 3; Deformed austenlte, strain-induced martensitic transformation.

Range 4: Stable austenlto, work-hardening due to defects. no martensite is formed.

peratures near $M_{8}$ the transformation mode is dominated by stressassisted nucloation on the samo sites responsible for the spontaneous cooling transformation. In a higher temperature reglme. however. strain-induced nucleation of martensite on new sites produced by plastic deformation (eg. slip bands, - crossings) is found. Above the $M_{d}$-temperature a deformation-induced martensitic transformation 18 impossible. It 18 worth mentioning that the equilibrium temperature $T_{0}$ depends on the chemical composition of alloy. the degree of order, the hydrostatic stress: the necessary undercooling $\Delta T$ to influenced by the nucleation and growth conditions for martensite inslde the matrix which depend on the external shear stress and strength of austenite (8). The quantitative connection between the change of $M_{0}$ and the external shear stress $\tau_{e}$ with 1 ts component $\tau_{e n}$ parallel to the martensitic shear $\phi_{n}$ is given by equ.l $(3,10,12)$.

$$
\frac{d M_{1}}{d r_{M}}-\frac{\Phi_{M}}{\Delta s_{M}}
$$


Due to the different transformation ontroples $48_{n}$ thlo effect 18 small in steels (Fig. 2 (2)). but large in Cu- or NITI-base shape memory alloys $(12,13)$

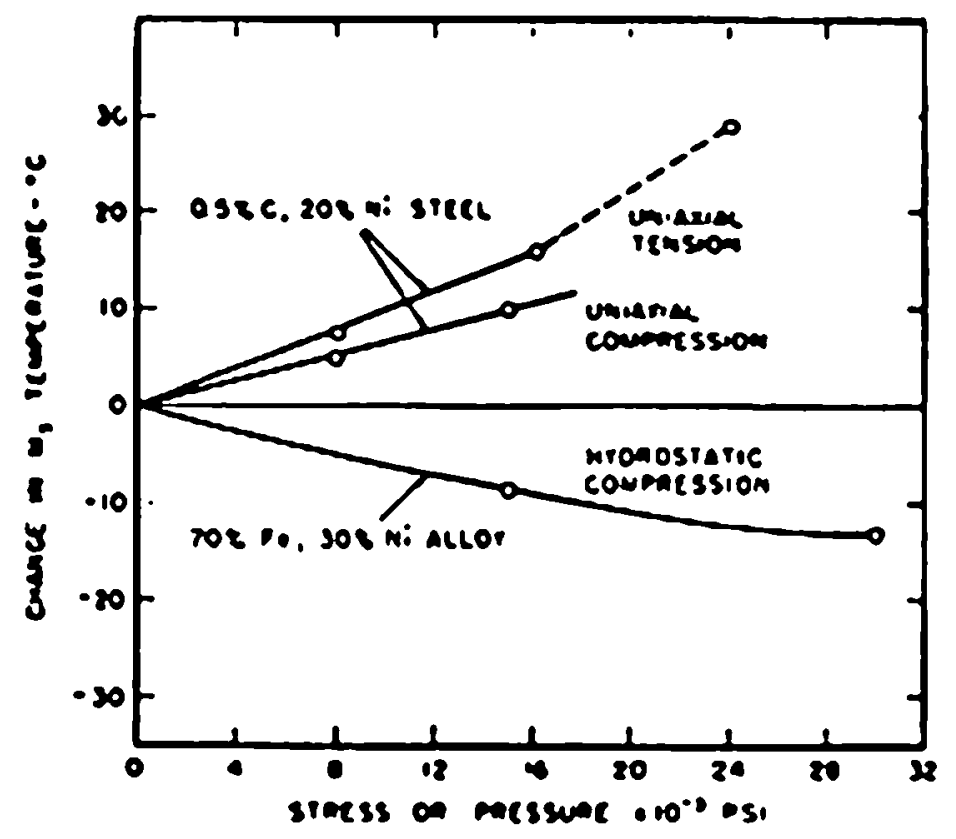

Fig. 2: Change in $M_{s}$ temperature as a Eunction of loading condition (2)

\section{Practure of Metactable Austenite}

The unusual combination of strength, ductility and toughness exhibited by metastable austenites have called much attention to the potential benefits of deformation-induced martensitic transformation. Consequences such as hlgh fracturs toughness. Increased fatlgue IIfo and TRansformation Induced Plasticity (TRIP) are discussed in the following.

Fracture Toughness and Fatigue strength

It has been shown for e.g. metastable austenitic stalniess steels (Pe-16Cr-13Ni, Fe $-18 \mathrm{Cr}-6.5 \mathrm{Ni}-0.19 \mathrm{C}(14)), \mathrm{Fe}-29 \mathrm{~N} 1-7 \mathrm{Al}$ alloye (15. 16). austempered ductile lrons with high amounts of retained metastable austenlte (17) that a local strain-inducod $\gamma$ - $\alpha$ transformation at the crack tip takes place (Fig. 3 (15)). This leads to a compressive Internal stress btate $\left(\Delta \overline{V_{\text {T }}} / \mathrm{V}_{\mathrm{V}}, 0\right)$ which relieves the crack tIp and impedes crack propagation. As compared to the deep-cooled fully martensitic microstructure (and stable austenite of 8 lightly modifled chemical composition) drastical decreases of the fatlgue crack growth rates are observed. Flg. $4 a$ exemplifies the stuation of an Fe-29Ni-7Al alloy: In addition, It roveals the high fracture toughnose which even increases with opecimen thlcknese, and the relatively high threshold value for fatigue crack growth of transformable austenltes (15). It must be mentioned. howevor. that the optimum effect is strongly temperature dependent. For a given stress intensity the arount of strain-induced martensite in the plastic zone decreases and the crack propagation rate increasos with increasing temperature. This 18 shown in P1g. 4b (14). 


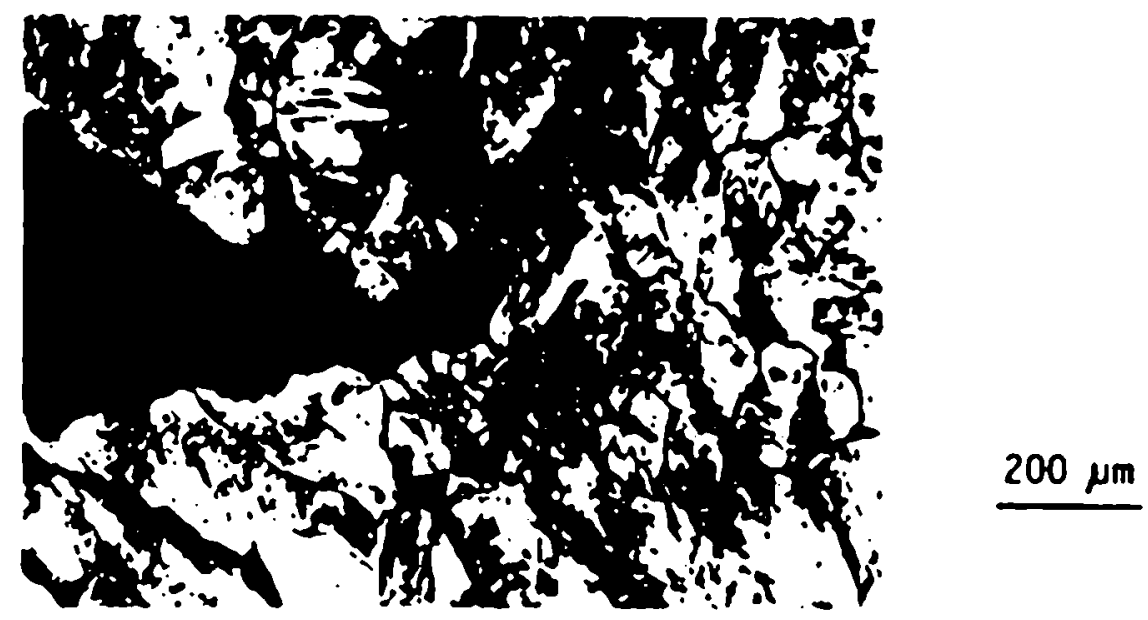

Fig. 3: Metallographic investigation of the transformation at the crack tip (15)
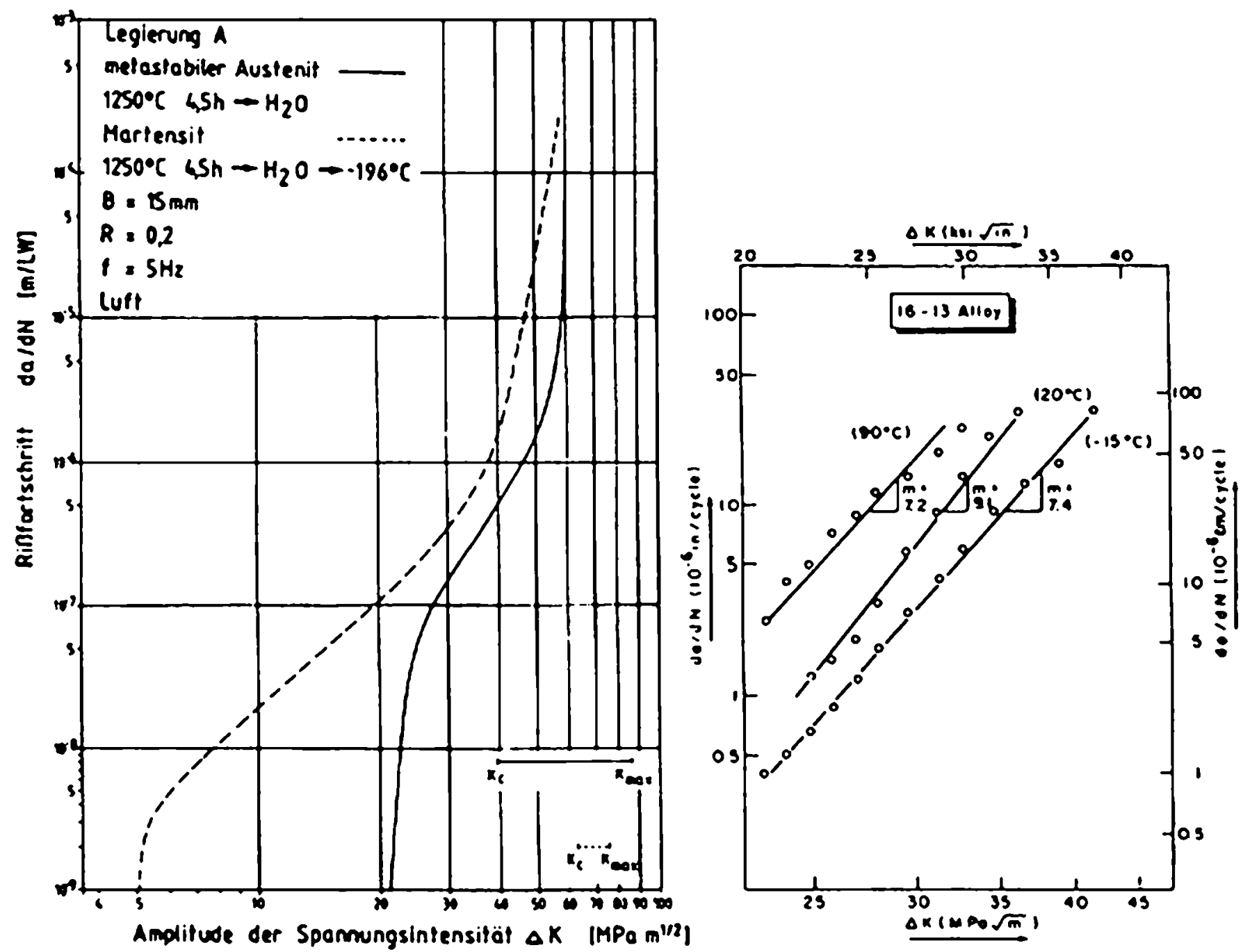

Fig. 4: Fatigue crack growth rates da/dN $=f(\Delta K)$ for cyclic Eension. a) Comparison of martensitic and austenitic structure ( $\mathrm{Fe}-29 \mathrm{Ni}-7 \mathrm{Al}(17))$, b) influence of test temperature (Fe-16Cr$13 \mathrm{Ni}, M_{s}=-75 " \mathrm{C}, M_{d}=+80 " \mathrm{C}(14)$ ) 
The influence of deformation-induced martensitic transformation on the fatigue properties of metastable austenltic steels is strongly dependent on the respective test conditions. Stress-controlled fatigue tests show that martensitic transformation is beneficlal to the fatigue life: on the contrary, the martensitic transformation shortens the fatigue life in the strain-controlled tests (18). In addition, it has been reported that the influence of deformation-induced martensitic transformation on the fatigue life lo closely related to the threshold number of cycles for the onset of martensite formation. However, up to now, critical conditions for the onset as well as kinetics of the deformation-induced phase transformation during fatigue are not well understood as compared to those during monotonic tensile or compressive deformation (19).

Transformation Induced Plasticity

Fig. 5 shows the stress-strain curves of the Fe-29Ni-0.26C austenitic alloy $\left(M_{s}=-60 " \mathrm{C}, M_{d}=+25 " \mathrm{C}\right)$ deformed in tension at various temperatures $(20)$. At -50 "C and at -70 "C, i.e. near the Ms temperature, large serrations due to the stress-induced martensitic transformation are observed before yielding of austenite. At elevated temperatures $(-10$ "C or -30 "C) fine serrations indicate that martensite is formed gradually with strain after yielding of austenite. Consequent ly a large elongation 18 observed which in the case of an Fe-25Ni-0.37C alloy can surpass 2008 (21).

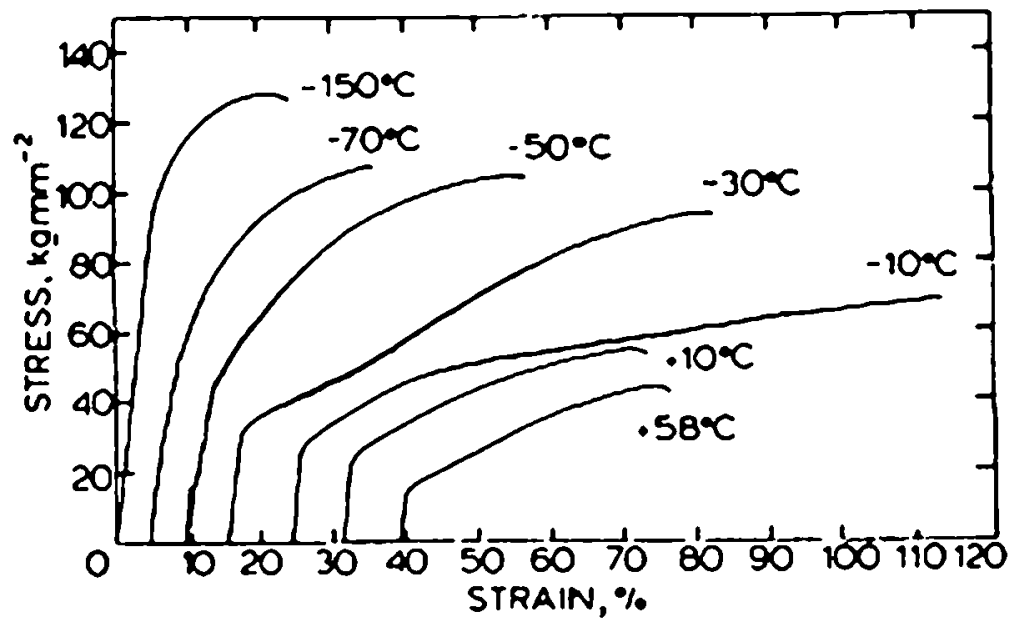

Fig. 5: Stress-8train curves of Fe-29Ni-0.29C alloy $\left.T M_{s}=-60 " C, M_{d}=+25 " C\right)$ during tensile tests at various temperatures, $\dot{\varepsilon}=5.5 \times 10^{-4} 8^{-1}(20)$

The tensile strength decreases with increasing test temperature, which corresponds to the decreasing volume fraction of martensite measured in the specimen after fracture. The total elongation exhibits a maximum at -10 "C. It is assumed that this temperature is just above $M_{5}^{F}$. when the transformation mode changes from a stress-assisted to a strain-induced one. Such an enhancement of elongation is mainly attributed to the suppression of necking ( $i . e$. the enhancement of uniform elongation) due to the continuous increase of work-hardening rate by the martensitic transformation. In addition, this behaviour effects a retardation of the initia- 
tion and the propagation of cracks because the stress

concentrations may be relaxed by the formation of preferential martensite variants in stress-concentrated regions.

Application to Practical Engineering

As mentioned above, the elongation and ductility can be enormously enhanced by TRIP, but the increase in yield strength has to be achieved by other means. Two-phase alloys of ausformed martensite (strength) and retained metastable austenite (TRIP) are the consequent development (6). In addition, ausaging, maraging. strain aging can also improve the strength of TRIP stcels. The result is the combination of tensile strength in the range of $2.000 \mathrm{MPa}$ and elongation above 258 , Tab. $1(6)$.

These properties combined with good corrosion resistance fulfil the requirements for pressure vessels. structural materials. chemical plants, off-shore developments, armour-plates, dampers. However, some undesirable consequences, most notably inhompgeneous yielding and extreme temperature sensitivity have hampered the practical development and application of the high-strength TRIP steels (22, 23). In the optimuin temperature range only a small amount of adiabatic heating is required to drastically alter the shape of stress-strain curve with an attendant serious loss of uniform ductility.

\begin{tabular}{|lllllll|}
\hline & $S i$ & $M n$ & $C r$ & $M O$ & $N I$ & Fe \\
\hline 0.3 & 2 & 2 & 9 & 4 & 8 & balance \\
0.2 & 2 & 2 & 13 & 3 & 9 & balance \\
0.25 & 2 & 2 & 13 & 3 & 8 & balance \\
\hline
\end{tabular}

Tab. 1: Typical high strength TRIP steel compositions (w/o)

For increasing fatigue strength (rotating or alternating bending) of structural components case-hardening of steels plays the most important role in practical application. Optimization efforts are always attended with e.g. the case-hardening depth, hardness profile, bulk and superficial c-content and retained austenite in the carburized layer. The origin and effects of retained austenite in these steels are comprehensively summarized by Razim (24) according to which maximum fatlgue life is found for the minimum amount of retained austenite. It is the consequence of the maximum amount of residual compressive stresses obtained by case-hardening. The stress-induced martensitic transformation of retained austenite in case-carburized steels is also described and a positive effect on fatigue strength is reported in comparison with deep-Erozen martensitic structures $(25,26)$.

\section{Tribological Properties of Metastable Austenite}

Basically. the martensitic transformation in frictioned surfaces of ferrous alloys is caused by two different effects. On the one hand, in ferritic steels $\left(M_{B}\right)$ ambient temperature) a friction- 
induced teinperature pulse can lead to austenitization and subsequent martensitic transformation. This martensite is deformed by frictional forces and the "white martensite" is formed. Its inner structure is characterized by a very high density of dislocations to which carbon atoms have segregated $(27,28)$.

In metastable austenitic steels exposed to Eriction below $M_{d}$ surface inartensite is caused by the friction-induced shear stress (29). This external shear stress is exerted parallel to the surface. It is proportional to the coefflclent of friction $\mu$ of the respective frictional system and the amount of the compressive stress $|-\sigma|$ :

$$
|-\sigma| \cdot \mu-\gamma_{0}
$$

Equ. 2

Superimposition of compressive stress and frictional shear stress creates a triaxial stress state. This external stress field gives a variable shear stress component to the actlve shear system of the martensite depending on its orientation. If this component surpasses a critical value $\tau$ am martensite nuclei form (Fig. 1 ). Therewith, the transformed volume, i. e. the thickness of the friction-induced martensitic layer is a function of the strength of austenite, its thermo-dynamic stability and the extent of the external stress field. Referring to wear the advantage of this phenomenon is that maximum strengthening 18 produced at the particular site which is exposed to the highest frictional loads and that renewable hard surface layers are created.

\section{Austenitic Manganese Steels}

The classic Hadfield steel (Fe-12Mn-1.2C) exhibits a marked wear resistance to heavy impact and gouging abrasion. It is not especially resistant to low stress abrasion $(30,31)$, because of the lack of hard dipersions or martensite. Systematic decreasing of austenite stability by decreasing the Mn-and/or C-content involves the formation of friction-induced martensite (Fig. 6). It leads to a continuous increase of surface hardness as well as of wear resistance (32). The plot of Fig. 6 confirms that the particular wear resistance cannot be related to the bulk hardness H. of the virgin austenite, but to the surface hardness $H_{0}+\Delta H$ resulting from work-hardening during oliding (29):

$$
W^{1} \sim H_{0}+\Delta H \quad \text { Equ. } 3
$$

At relatively low frictional loads the linear relationship indicates that the continuous transition from pure work-hardening of austenite ( $12 \mathrm{Mn}, 8 \mathrm{Mn}$ ) to friction-induced martensitic transformation in a thin frictioned layer $(5 \mathrm{Mn})$ does not change the wear mechanism. Microcutting and mlcroploughing predominate. If, however, the transformed layer exceeds a certain thickness, a brittle fracture component arises and the wear resistance decreases independently of the maximum surface hardness (Fig. 7).

Differences in wear mechanisms are described by the coefficient of wear $k$ which expresses the probability of decohesion of matter in the asperity area $A$ (34). (Ao is the nominal surface of the sliding material.) It has been proposed to subdlvide the coefficient of wear $k$ into two components characterizing deformation $\left(k_{d}\right)$ and brittle fracture $\left(k_{f}\right)(35,36)$ : 


$$
W=k \cdot \frac{A}{A_{0}}=k \cdot \frac{\sigma}{H_{0}+\Delta H}=\left(k_{0}+k_{0}\right) \cdot \frac{\sigma}{H_{0}+\Delta H}
$$

Equ. 4

\begin{tabular}{|c|c|c|c|c|c|c|}
\hline Alloy no. & $\begin{array}{c}\text { Ond } \\
M\end{array}$ & $c_{c}^{\alpha}$ & $\begin{array}{l}\mathrm{MP} . \mathrm{M} / \mathrm{O} \\
\mathrm{Si}\end{array}$ & $\Delta \sqrt{\alpha}$ & Fion & $\overline{\mathbf{W}} 10, d$ \\
\hline $\begin{array}{l}12 \mathrm{~m} \\
8 \mathrm{~m} \\
6 \mathrm{~m} \\
5 \mathrm{~m} \\
1 \mathrm{~m} \\
0 \mathrm{mc} . x\end{array}$ & $\begin{array}{r}13.1 \\
7.25 \\
6.03 \\
1.98 \\
3.97 \\
0.30\end{array}$ & $\begin{array}{l}1.14 \\
1.16 \\
1.16 \\
1.16 \\
1.15 \\
0.69\end{array}$ & $\begin{array}{l}0.43 \\
0.33 \\
0.29 \\
0.31 \\
0.29 \\
0.22\end{array}$ & $\begin{array}{l}1-196 \\
--198 \\
-196 \\
-57 \\
-31 \\
-\quad 2\end{array}$ & $\begin{array}{l}223.3 \\
221.3 \\
223.8 \\
219.3 \\
218.1 \\
220.2\end{array}$ & $\begin{array}{l}221.3 \\
224.3 \\
228.8 \\
368.5 \\
436.0 \\
524.3\end{array}$ \\
\hline
\end{tabular}
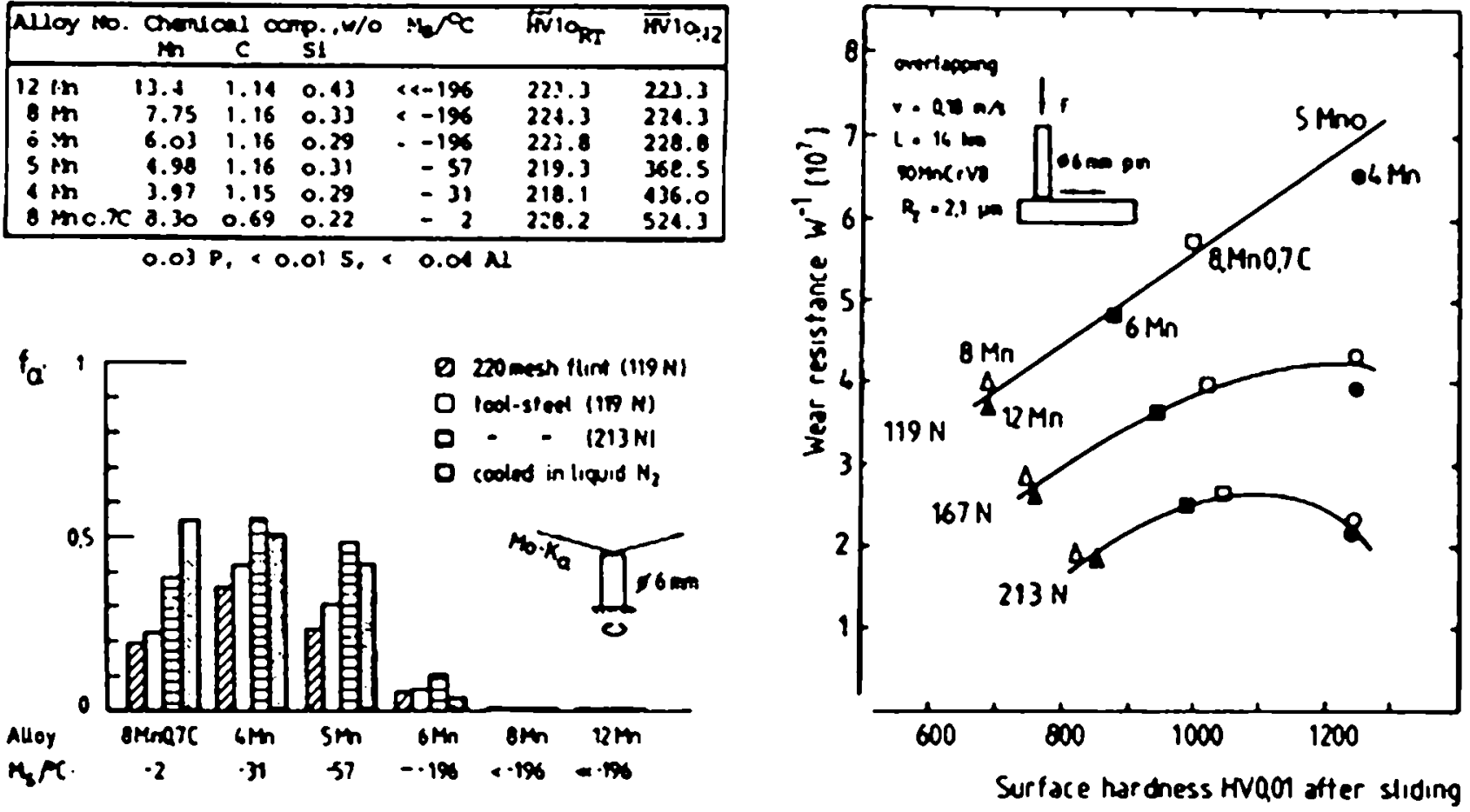

Fig. 6: a) alloys investigated Fraction $\mathrm{F}_{a^{\prime}}$ due to friction or cooling in liquid $\mathrm{N}_{2}$ vs. the degree of metastabilitiy of austenite. cl influence of the applied load on wear reslstance and surface hardness after dry sliding
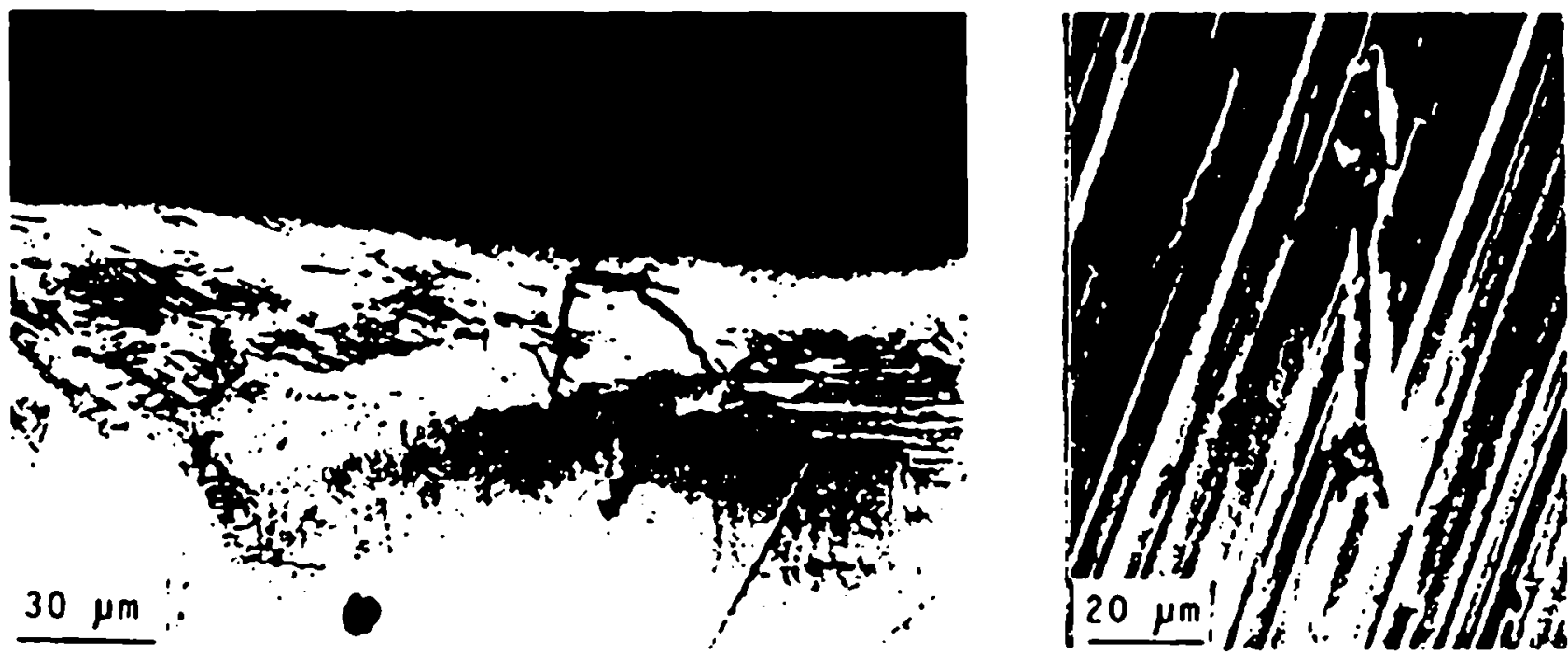

Fig. 7: Brittle fracture in a martensitically transformed surface layer of the alloy $4 M n$ exposed to dry sliding, $M_{s}=-31$ "C, toolsteel counterpart, app. pressure $p^{*}=38.2 \mathrm{MPa}(32)$ a) LM, b) SEM 

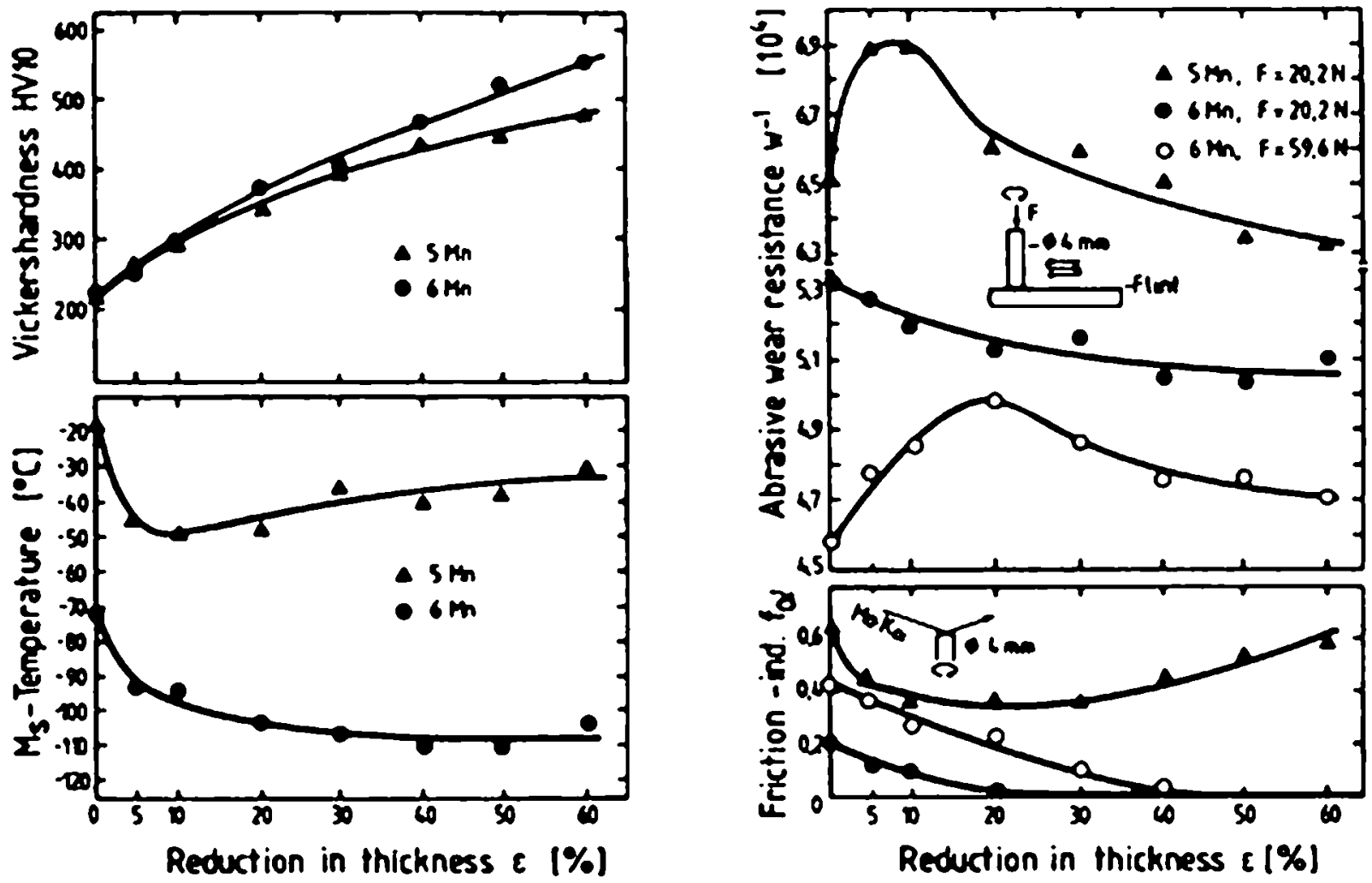

Fig. 8: a) Influence rolling of above $M_{d}$ on Vickers hardness and Ms. b) plot of abrasive wear resistance and amount of frictioninduced martensite vs. deformation of austenite above $M_{d}$

It seems to be reasonable from the results presented that in less stable high-carbon austenitic alloys this brittle fracture component controls the wear rate. It is most effective in thick martensitic layers as unstable crack growth cannot be prevented. obviously. in these alloys the change in hardness due to the friction-induced martensitic transformation is overcompensated by a decrease in fracture energy of the transformed layer (36). This is most pronounced during wear of metastable austenites at $h$ lgh loads.

Predeformation of these austenites e.g. by rooling above the Md temperature ( $M_{d} \geqslant 400^{\circ} \mathrm{C}$ ) which influences the $M_{s}$ temperature by work-hardening $d \sigma / d \varepsilon_{f}$ internal stresses $d \tau_{i} / d \varepsilon_{\text {, }}$ and new possible nucleation 81 tes for martensite dnN/de at silp bands or slip band crossings $(37,38)$ seems to be a suitable preconditioning process for better accommodation of austenite to the conditions of the respective wear system (39) (Fig.8):

$$
\frac{d M_{1}}{d \varepsilon}=-\frac{\partial \Delta T}{\partial r_{y}} \cdot \frac{\partial r_{y}}{\partial \varepsilon}+\frac{\partial \Delta T}{\partial \pi_{1}} \cdot \frac{\partial r_{1}}{\partial \varepsilon}+\frac{\partial \Delta T}{\partial n_{N}} \cdot \frac{\partial r_{Y}}{\partial \varepsilon}
$$


Retained Austenite in Alloys Approved in Service

The results obtained in austenitic model alloys mentioned above can easily be related to multi-phase alloys in practical engineering consisting of more or less amounts of retained austenite.

Ledeburltic high-alloy Fe-Cr-C tool-steels consist of a fine dispersion of $M_{3} C_{3}$-carbldes embedded in a hardened, mainly martensitic matrix. It has been shown that an increasing amount of retained austenite leads to a significant decrease in wear rate (F1g. 9, X210Crl2 + 12 v/o TiC) (40).

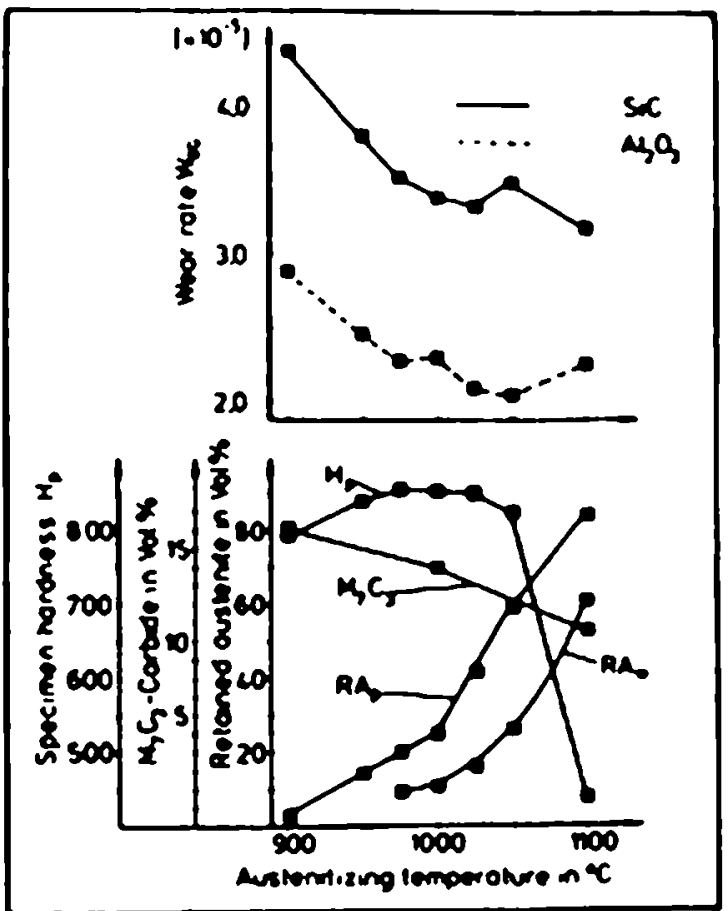

Fig. 9: a) abrasive wear rate in dependence of macrohardnes8, amount of carbides and retained austenite before ( $R A_{p}$ ) and after

$\left(R A_{W}\right)$ sliding on $\mathrm{SiC}$ and $\mathrm{Al}_{2} \mathrm{O}_{3}$ b) LM of $\times 210 \mathrm{Crl} 2,30^{\prime} / 900^{\prime \prime} \mathrm{C} / 011$
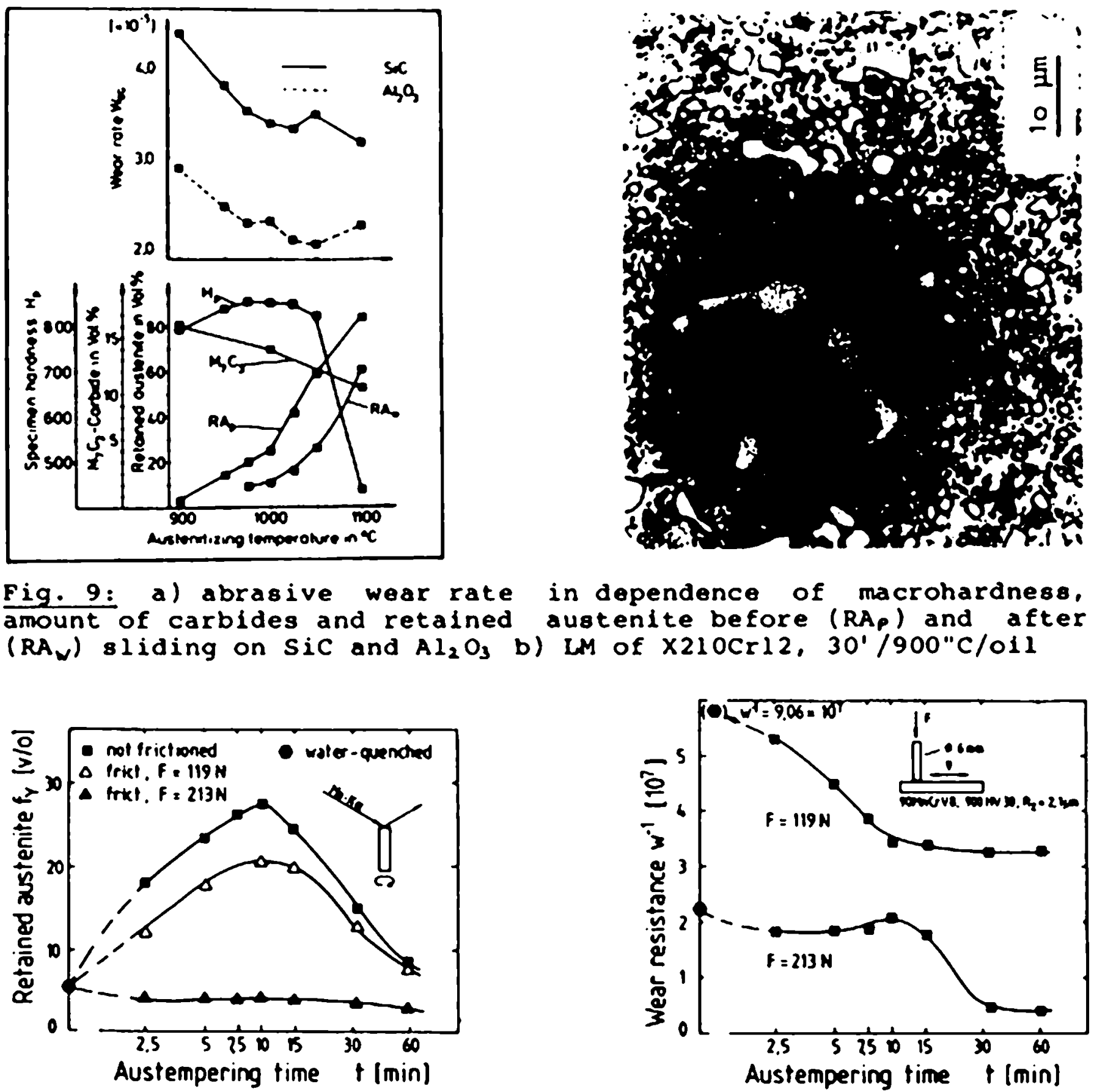

Fig. 10: Connection between the amount of retained austenite before and after friction and the sliding wear resistance as a function of austempering time ( $T=400$ "C). 
Austempered ductlle irons (a.g. GGG 100BA) comblne excellent mechanical properties such as tensile strength between 800 and $1600 \mathrm{MPa}$, elongations at fracture rangling from 16 to 18 , fatigue IImits comparable to those of tempered wrought seels with very high wear resistance under abrasive conditions $(41,42,43)$. These characterletics orlginate from the speclal micostructure. It con$818 t s$ of about 12 v/o carbon sperulites and a fine-scaled mixture of balnite and austenite which is obtalned by austenitization and subsequent austempering in the bainite range. Depending on the applied frlctional shear stress, the amount of retalned austenite and its thermo-dynamic stablilty the wear reslatance of a tough austempered ductile iron can approach values of quench-hardened ductile iron (Fig. $10(42)$ ).

In roller bearling steels (0.9. 100Cr6. Fig. 11 (44)) as well as in gear whoel steols (0.9. 16MnCr5, 15Crnit ) transformation of retained austenite due to tho Hertzian contact otross fleld during service has been observed. However, no worth mentioning influence on dimensional stabllity or performance 18 found if the correct heat troatment is conducted bofore.

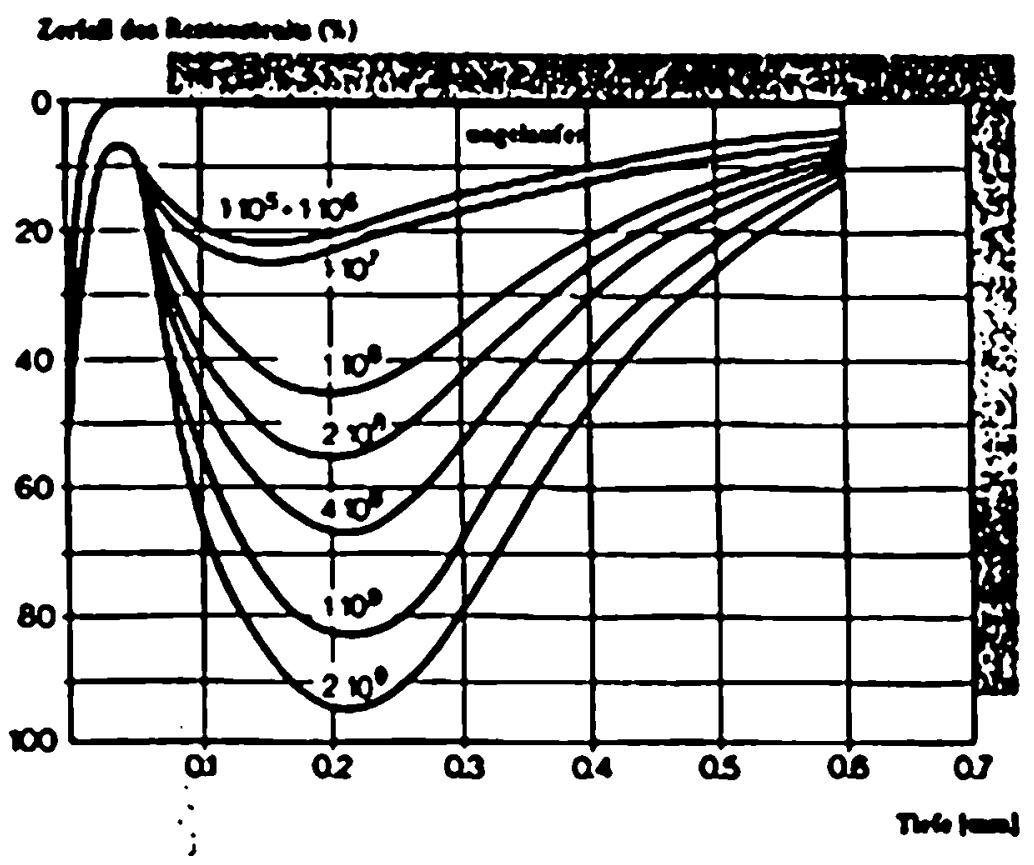

Flg. 11: Traneformation of the rotained austenlte in 100 Cr 6 in dependence of the depth below the roller path and revolutions, contact stress $\sigma_{y}=3800 \mathrm{MPa}$ (44)

\section{References}

(1) E. Sche11: Z. Anorg. Chem. 207 (1932) 21

(2) J. R. Patel. M. Cohen: Acta metall. I (1953) 531-538

(3) U. Dehlinger: Theoretische Metallkunde, 1. Edition, Springer, Berlin, 1955. P. 168

(4) L. Kaufman, M. Cohen: Prog. Met. Phys. 7 (1958) 165-246 
(5) E. Hornbogen, G. Wassermanns 2. Metalikde. 47 (1958) 427-433

(6) V. F. Zackoy, E. R. Parker, D. Fahr, R. Busch, Trans. ASM 60 (1967) 252-259

(7) I. Tamurai Motal Science 16 (1982) 245-253

(8) E. Hornbogens Acta metall. 33 (1985) 595-601

(9) Y. N. Dastur. W. C. Lesl1es Met. Trans. 12 A (1981) 749-759

(10) E. Hornbogen: 2. Metallkde. 75 (1984) 739-746

(11) G. B. Olaon. M. Cohen: J. Less-Common Met. 28 (1972) 107-118

(12) E. Hornbogens Arch. Eisenhutenwes. 43 (1972) 307-313

(13) H. Warlimont. L. Delaey, R. V. Krishnan, H. Tas: J. Mater. Sci. 9 (1974) 1545-1555

(14) A. G. Pineau, R. M. Pelloux, Met. Trans. 5 (1974) 1103-1112

(15) I. Wittkamp, E. Hornbogen: Prakt. Metallographle 14 (1977) 237-250

(16) E. Hornbogens Acta metal1. 26 (1978) 147-152

(17) K. H. Bowe, E. Hornbogen, M. Huhner: konstr. + globen 12 (1987) 14-19

(18) G. B. Olson, R. Chait, M. Azrin, R. G. Gagnes Met. Trans. IlA (1980) 1069-1080

(19) K. Tzusak1, T. Maki, I. Tamuras J. Phys. 12 (1982) 423-428

(20) I. Tamura, T. Maki. H. Hato: Trans. Iron steel Inst. Japn. 10 (1970) 163-171

(21) I. Tamura, Y. Tomota. M. Ozawas The microstructure and design of alloys. The Metals Soclety. London, 1974. P. 540

(22) M. Azrin, G. B. Olson, R. A. Gagnes Mat. Sci. Eng. 23 (1976) 33-41

(23) G. B. Olson, M. Cohen: Met. Trans. 13A (1982) 1907-1914

(24) C. Razims HTM 40 (1985) 150-165

(25) H. Brand18, H. Reimers, W. Schmldt. A. Von den steinen: Ibld. 38 (1983) $63-70$

(26) H. Brand18. H. Dietrlch, W. Schmldt: ibid. 40 (2985) 57-63

(27) H. Uetz. K. Sommer: Mineralbleechnik 12 (1972) 3-25

(28) E. Minuth. E. Hornbogen: Prakt. Metallogr. 13 (1976) 584-598

(29) H.-M. Bauschke, K.-H. Zum Gahr, E. Hornbogen, Z. Metallkde. 72 (1981) $1-12$

(30) H. Berna, H. F. Klärner, E. Schmidtmann: Arch. Elsenhuttenwes. $38(1967) \quad 447-453$

(31) D. E. Diesburg, F. Borik: Symp. Materials for the Minling Industry. ClImax Molybdenum Company. Vail, Co, (1974) 15-41

(32) N. Jost. I. Schmidt: Wear 111 (1986) 377-389

(33) I. Schmidt: 2. Metallkde. 75 (1984) 747-754

(34) J. P. Archard: J. Appl. Phys. 24 (1953) 981-988

(35) E. Hornbogen: 2. Metalikde. 66 (1975) 507-510

(36) K. H. Zum Gahr: ibld. 69 (i978) 643-650

(37) H. Onodera. I. Tamura: J. Phys. 12 (1982) 337-342

(38) R. D. Wollmann, J. R. C. Gulmaraes, Scripta Met. 7 (1973) 355-360

(39) I. Schmldt. M. Wl thelms 1b1d. 78 (1987) 127-130

(40) H. Berns, W. Trojahm: Z. Werkstofftechn. 24 (1983) 382-389

(41) P. Mayr. H. Vetters. J. Wallas Gleberelforschung 38 (1986) 86-92

(42) I. Schmidt, A. Schuchert, 2. Metallkde. 78 (1987) 871-875

(43) S. Shepperson. C. Allens Proc. Int. Conf. on Wear of Materia 18. ASME, K. C. Ludema (ed.). Houston $T X$ (1987) 573-583

(44) G. E. Hollux, A. P. Voskamp, E. Ionnides: Kugellager-Zeitschrift 231 (1989) 20-27 